\title{
To Study the Cause of Teachers Grievances in Secondary School
}

\author{
Ghazala Mubarak, Prof. Dr. Syed Abdul Aziz, Imranulla Shariff \\ In The Partial Fulfillment Of The Requirements For The Degree Of \\ Master Of Science (M.S.) In Quality Management (Social Sciences) \\ Presented To Hamdard Institute Of Education And Social Sciences Hamdard University Karachi
}

\begin{abstract}
In the study teacher's grievances in secondary schools and their causes are discussed in detail. Why teachers face difficulties in showing their performances? It is observed that there are so many causes due to which teachers' grievances persist in secondary school. By data collection through questionnaire and interview, it is concluded that most important causes are pay inequities, favoritism, workload differences and management attitude. Suggestions for management and for teachers have also discussed and recommendation also mentioned in the paper.
\end{abstract}

\section{Introduction}

Grievances can be created when two or more people work together. There are different reasons of grievances at work place. Here, I will study the grievances of teachers which can be effect on their performance and image of the institution. Mostly female teachers can be seen in the secondary schools, because females required easy and short duration jobs due to the timing and low work pressure. But if we discuss from teachers then mostly they will reply that they have economic problems at their homes that's why they come out from the rest state in such a different environment.

If we talk about the environment, then it is general thinking of the people that teaching is very calm and relaxing job. Here I will discuss the problem of teachers with in the schools and study the grievances along with reasons, which they face and their performance become lay down.

When teachers of different ages and with different qualification work together especially women may confront with grievances.

\subsection{Reasons Of Grievances}

There are many reasons of grievance between teachers which are discussed as under:

1. Pay scale inequities

2. $\quad$ Timing

3. Leave allowed

4. Management attitude

5. Favoritism

6. Age discrimination

7. Behavior of seniors

8. Work Load differences

9. Parent attitudes towards teachers

10. Backbiting

11. Indiscipline attitude

12. Nature of teachers

13. Promotion

14. Injustice

15. Religious differences

\subsubsection{Pay Scale Inequities}

Different teachers come from different background, their education and experiences are different, some time few teachers with same qualification but have different area of experience may get different salary package. Mostly it is also observed that with similar education and experiences teachers are getting different salaries. Different pay scale can cause grievance between teachers.

\subsubsection{Timing}

Timing can be varied for junior or senior section, there may be change in working hour or working days, it may cause grievance between teachers. Teachers may face conflicts who are allowed to go early or to come late. 
Example: Brady and DTU's point grievance list include claims that:

Teachers are being forced to stay after school end and stand at the buses for afternoon duty beyond their normal work hours.

\subsubsection{Leave allowed}

Mostly it has observed that secondary private school teachers do not get proper casual leave, seniors can get leave with pay but juniors or new employees can not be allowed for leave with pay even in case of emergency.

\subsubsection{Management attitude}

In females it seems that they get different type of attitude from the management especially if female are in management sector, teachers can be have mostly strict behavior, that can cause problem and make difference in their performance.

Example:

Brady and DTU's point grievance list include claims that ${ }^{1}$ :

- $\quad$ Teachers at the overage academies do not have duty-free lunches nor do they have daily planning periods

- $\quad$ Teachers are missing instruction time because they have to perform monitoring duties in cafeterias

- Teachers do not have the printer cartridges and copy machine access they need to create materials

- $\quad$ Some teachers are being asked to teach a class during their planning period and offered pay at their hourly rates

\subsubsection{Favoritism}

Favoritism is another cause which confront towards all the teachers, it can be caused if friends or relative work in the same premises at the same section or either in junior and senior section.

\subsubsection{Age discrimination}

People of different ages if work together then they can be effect by conflict due to energy in work, In this case those who are older feel that they become less important from inexperience juniors just because of age and freshness.

\subsubsection{Behavior of seniors}

In an institution where juniors and seniors work together, it seems that seniors mostly express their impression and want to be dominant from juniors, then juniors or new employees face difficulty in adjustment in the same environment.

\subsubsection{Work load differences}

Work load can be different due to very low difference in salary; this can cause grievances between those teachers who work with full dedication but getting up to mark salary package according to their hard work.

Example - 1:An article related to the work load grievance ${ }^{2}$ :

The county teachers have complained that they've been working long hours because the lesson plans have not been available until just weeks before they are to be taught and the website to access those lessons has been difficult to use.

"We are looking for solutions to the huge issues that are facing our folks, the issue of workload, the issue of curriculum not being ready," said Abby Beytin, president of the Teachers Association of Baltimore County.

The grievance, filed on behalf of the county's 8,700 teachers, is uncommon in its scope, according to Adam Mendelson, a spokesman for the Maryland State Education Association, which represents county teachers. While teachers unions regularly file grievances, they usually are only on behalf of an individual employee or a small group of teachers.

Mendelson said he is not aware of any other grievance related to the Common Core implementation in Maryland. The standards were adopted by Maryland and 45 other states.

The county union documented the extra work by asking teachers to fill out work logs over a two-week period. Beytin said the logs show that teachers are sometimes working 30 to 40 extra hours during that time.

While teachers are normally expected to work additional time outside of their classroom schedule, the hours are much greater this year, according to the union. 
The teachers' contract specifies that when teachers are expected to implement a new curriculum or program they must be given training a reasonable period of time in advance. In addition, the contract says the county must provide the materials and texts in advance.

Beytin would not provide a copy of the grievance to The Baltimore Sun or say what the union seeks from the school board.

Baltimore County School Superintendent Dallas Dance said Wednesday that the school system received the grievance late Tuesday night. Dance and school board President Lawrence Schmidt said in a statement Wednesday that the system is reviewing the grievance and "it would be premature to comment on its contents."

"We will be looking at the remedy, which every grievance must have, to determine what federal/state versus local concerns is," the statement said.

Example - 2:Brady and DTU's point grievance list include claims that ${ }^{3}$ :

Teachers particularly in art, music and physical education are seeing abnormally large class sizes in middle school

\subsubsection{Parent attitudes towards teachers}

Few teachers are favorite for students similarly parents also admire only those teachers, teachers who are strict and not favorite of students they feel bad because of different attitude.

\subsubsection{Backbiting}

Backbiting is the bad habit as a human being, teachers also suffer with this bad feature, and those who want to do work in good environment they cannot tolerate this type of unethical behavior.

\subsubsection{Indiscipline Attitude}

Those who work in discipline manner, cannot bear indiscipline behavior of teachers, that why teachers who are lazy, irregular, indiscipline can be irritating for discipline members.

\subsubsection{Nature of Teachers}

Different teachers have different nature and are of different personality, if they cannot be with similar nature people then they avoid those who are not fulfilling their demands and cannot understand their behavior.

\subsubsection{Promotion}

Promotion or increment at the same level create serious grievance between teachers, who worked hard and also senior but cannot receive increment as compare to junior one.

\subsubsection{Injustice}

Injustice between compatible and non-compatible teachers seems conflicts in the school, those who are talented some time face injustice attitude of seniors or management.

\subsubsection{Religious Differences}

Teachers come from the different family or religious back ground they feel bad if someone give any negative remarks related to religion. People with different religious status feel difficult to work together.

\subsection{Method Of Data Collection}

\section{Methodology}

In the project data has been collected through questionnaire, which was circulated to secondary school teachers. Interviews were also conducted from secondary school teachers and their views and main point has been discussed.

\subsection{Data Analysis Tool}

Data collected from questionnaire and interviews were analyzed using Pareto Chart to identify the vital few causes of grievance from trivial many.

Table 1

\begin{tabular}{|c|c|c|}
\hline S.No & Cause of Grievances & Frequency \\
\hline 1 & Pay Scale Inequities & 20 \\
\hline 2 & Work load differences & 11 \\
\hline 3 & Favoritism & 11 \\
\hline 4 & Management attitude & 7 \\
\hline
\end{tabular}




\begin{tabular}{|c|c|c|}
5 & Timing & 6 \\
\hline 6 & Leave allowed & 6 \\
\hline 7 & Promotion & 5 \\
\hline 8 & Injustice & 5 \\
\hline 9 & Indiscipline attitude & 5 \\
\hline 10 & Backbiting & 4 \\
\hline 11 & Nature of Teachers & 2 \\
\hline 12 & Behavior of seniors & 2 \\
\hline 13 & Parent attitude among teachers & 2 \\
\hline 14 & Age discrimination & 1 \\
\hline 15 & Religious differences & 0 \\
\hline & Total & 87 \\
\hline
\end{tabular}

Figure 1

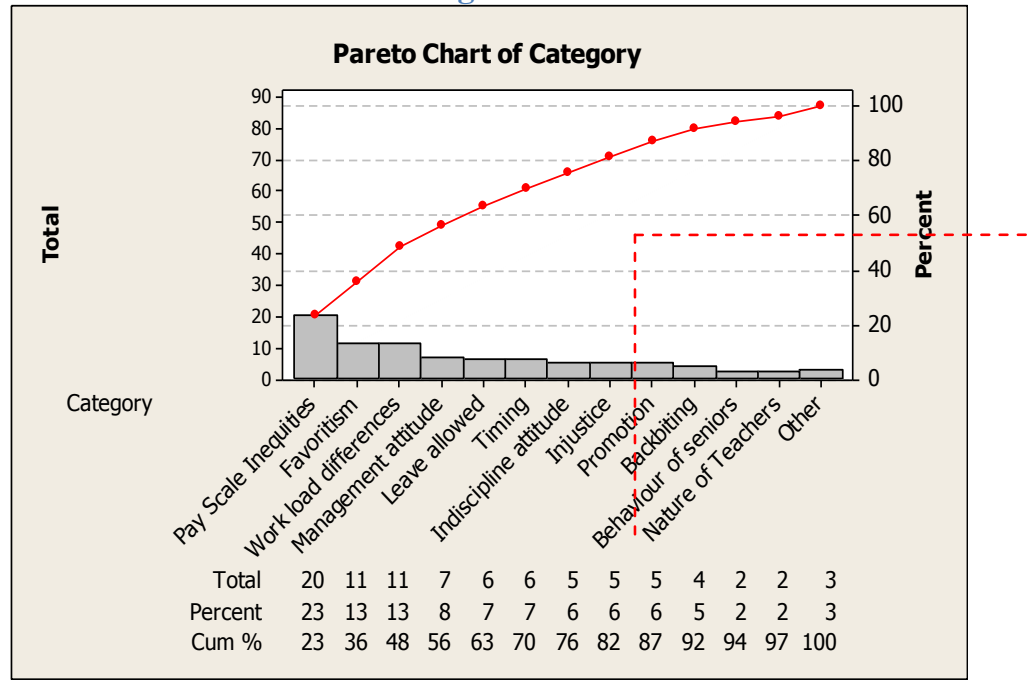

III. Interpretation Of Results

\subsection{Results}

\subsubsection{Result Of Questionnaire}

From the results shown by Pareto Chart it is evident that Vital Few causes which are the reasons behind grievances among teachers are as follows:

- $\quad$ Pay Scale Inequalities

- Favoritism

- Work Load Differences

- Management Attitude

- $\quad$ Leave Allowed

- $\quad$ Timing

- Indiscipline Attitude

\subsubsection{Result Of Interview:}

From the result of interview it is concluded that most of the teachers confront from grievances due to following most common reasons:

- $\quad$ Pay Scale Inequalities

- Favoritism

- Management attitude

- $\quad$ Nature of Teachers

- $\quad$ Backbiting

- Work load differences

\subsection{Conclusion}


In the school level it is common that teachers have grievances between them due to different reasons. Those causes are in different nature and they can be handled at the first stage but it seems that some time they become unresolved for the long time, they we may have the extreme situation. Politics between female teachers highly observed in the school premises, that can cause grievance and environment of the school become worst due to bad situations.

\subsection{Suggestions For Management}

\section{Suggestions And Recommendations}

By different methods we can resolve the teacher's grievance

- $\quad$ By making a proper salary package according to education, experience, work load, and performance.

- After observation we should give positive feedback to the teachers to overcome their mistakes and to enhance their abilities.

- We must counsel them and guide them according to their level of understanding.

- Management should have the accurate reason of favoritism on the basis of performance.

- Management must consider both side points of views before taking any serious action against teachers.

- Management should be flexible in granting leave; those who are not habitual to be absent their leave must be considered.

- Work load should be equal for seniors and juniors if they are getting same salary packages.

- $\quad$ There should be similar attitude for seniors and juniors, because management has very important role in communication between senior and junior teachers.

- $\quad$ Timing and working hour should be similar, because those who give extra time for the institute they are expecting more grant from the management, sometime their extra working hour not considered by management.

- Management should resolve the grievance as soon as it appear, those who fill the problem, they should not to be disturb for their work.

- Management should appreciate the teacher if they have shown good results and if they are regular in their work submission

\subsection{Suggestions For Teachers}

- $\quad$ All the teachers should be open minded and friendly in nature

- $\quad$ They should understand the mental level of other teachers and of the management.

- $\quad$ They should demand the salary according to their performance.

- $\quad$ They must use proper channel to convey their problems

- $\quad$ Senior teachers should provide space of work to junior teachers

- Teacher should not to be jealous from more efficient and responsible teachers; they should enhance their performance according to good performer.

- Teachers must follow the rules and regulation of the institution; they must understand the critical position of management.

- $\quad$ Teachers must not show bad attitude towards students if they have problem with other teachers or with management.

- $\quad$ Teacher must follow the regular timing and not to be break the rules

- $\quad$ They should try to give their high grade performance to enhance the good-will of the school.

- Teachers are in the school who make the good working environment, they should co-operative and friendly to improve better working conditions

- In following way teacher can file the grievance due to work load ${ }^{4}$ :

- Elementary Schools - Most schools are programmed for either seven or eight periods per day. In sevenperiod schools, you are scheduled for a daily duty-free lunch period and five preparation periods per week. In eight-period schools, in addition to the daily duty-free lunch period and preparation period, you receive one professional period per week. Schools may use an SBO to change the number of periods in a day but principals cannot do it unilaterally. If you believe you have been given an incorrect assignment, speak to your chapter leader immediately about filing a grievance.

- JHS/IS/MS Schools - You should receive your teaching program no later than five school days before the end of the school year. Your teaching program must consist of a maximum of 25 teaching periods, five preparation periods, five professional periods and five duty-free lunch periods per week. In Title I schools, senior staff members who qualify must be programmed for 22 teaching periods, eight preparation periods, and five duty-free lunch periods. If you think you qualify for the additional preparation periods, you should check with your chapter leader. Your chapter leader also can help you file a grievance if your teaching 
program does not follow contractual guidelines (e.g., more than three teaching periods in a row, four working assignments in a row, etc.).

- High Schools - You should receive your teaching program no later than the end of school on the next to last day of the term. Your teaching program must consist of a maximum of 25 teaching periods, five preparation periods, five professional periods and five duty-free lunch periods. However, if you have a reduced teaching program (e.g., a compensatory-time position), you receive one preparation period for every five periods you teach. Speak to your chapter leader to file a grievance if your teaching program does not follow contractual guidelines (e.g., more than three teaching periods in a row, four working assignments in a row, etc.).

- Grievances regarding teacher programs must be filed within two days from knowledge, so speak to your chapter leader as soon as you believe that your program does not follow contractual guidelines.

\subsection{Recommendations}

After the study it is observed that there are few most important reasons of grievances which have to be discussed in detail. It is recommended that more detailed study should done in pay inequities problems, there deep and long lasting effects on teachers, then work load differences, that must be according to their abilities but benefits should also be there. Another important factor is favoritism, which is some time neglected and employee become confused in favorite worker or in good performer, mostly management favor only those who work sincerely and with complete dedication but other employees think that about that employee which become favorite, in this case that person cannot work in such a political environment.

\section{Acknowledgement}

I take this opportunity to express my profound gratitude and deep regards to my guide Mr. Imranulla Shariff for his exemplary guidance, monitoring and constant encouragement throughout the course of this thesis. The blessing, help and guidance given by him time to time shall carry me a long way in the journey of life on which I am about to embark.

I also take this opportunity to express a deep sense of gratitude to Mrs. Tahmeen, Principal of Al-Aira Group of Schools, for her cordial support, valuable information and guidance, which helped me in completing this task through various stages.

I am obliged to staff members of Al-Aira Group of Schools, for the valuable information provided by them in their respective fields. I am grateful for their cooperation during the period of my assignment.

Lastly, I thank almighty Allah, my parents, brother, sisters and friends for their constant encouragement without which this assignment would not be possible.

\section{References}

[1] http://jacksonville.com/news/metro/2013-09-18/story/duval-teachers-complain-about-class-sizes-planning-time-and-more

[2] http://articles.baltimoresun.com/2013-11-20/news/bs-md-co-teacher-grievance-20131119_1_file-grievance-county-teachersteachers-association

[3] http://jacksonville.com/news/metro/2013-09-18/story/duval-teachers-complain-about-class-sizes-planning-time-and-more

[4] http://www.uft.org/our-rights/know-your-rights/teacher-programs 